\title{
Analytes of Interest and Choice of Dose: Two Important Considerations in the Design of Bioequivalence Studies with Atorvastatin
}

\author{
Kuan Gandelman ${ }^{1 *}$, Bimal Malhotra ${ }^{1}$, Robert R. LaBadie ${ }^{2}$, Penelope Crownover ${ }^{1}$ and Tamie Bergstrom $^{1}$
}

${ }^{1}$ Pfizer Inc., New York, New York

${ }^{2}$ Pfizer Inc., Groton/New London, Connecticut

\begin{abstract}
Atorvastatin is an oral lipid-lowering agent. A Small Tablet (ST) formulation and a Chewable Tablet (CT) formulation have recently been developed and tested in two single-dose bioequivalent (BE) studies (10 mg and $80 \mathrm{mg}$ ), each in 76 healthy volunteers. Plasma samples were only analyzed for atorvastatin in ST studies, and simultaneously for both atorvastatin and ortho-hydroxyatorvastatin in CT studies. The results showed the ST and the CT formulations were each bioequivalent to the current Marketed Tablet (MT) formulation, at the lowest (10 mg) and the highest $(80 \mathrm{mg})$ doses. For the CT formulation, both atorvastatin and its metabolite achieved BE at both doses. Although the metabolite $\mathrm{BE}$ is not warranted, supportive metabolite data may be needed depending on the degree of divergence in formulations from its MT formulation. Furthermore atorvastatin has linear PK with respect to AUC; however, $\mathrm{C}_{\max }$ is nonlinear with a greater than dose-proportional increase. Therefore, to ensure the desired sensitivity to detect formulation differences, BE studies with atorvastatin should be conducted at the highest dose.
\end{abstract}

Keywords: Atorvastatin; Bioequivalence; Marketed tablet; Small Tablet; Chewable tablet

\section{Introduction}

Atorvastatin is a lipid-lowering agent, approved for treatment once daily at 10-80 $\mathrm{mg}$ doses in adults and at 10-20 mg doses in children aged 10 years or older [15]. Following oral administration, atorvastatin is rapidly absorbed, and maximum plasma concentrations are achieved within 1 to 2 hours. Atorvastatin is extensively metabolized by cytochrome P450 3A4 to active metabolites: ortho- and parahydroxyatorvastatin. Approximately $70 \%$ of the circulating inhibitory activity for HMG-CoA reductase is attributed to these active metabolites [15]. In vitro inhibition of HMG-CoA reductase by orthoand para-hydroxylated metabolites is equivalent to that of atorvastatin. Ortho-hydroxyatorvastatin is the predominant active metabolite in systemic circulation [12,18]. In a single-dose study of 2.5 to $120 \mathrm{mg}$ doses [16] and in multiple-dose studies of 2.5 to $80 \mathrm{mg}$ dose [15], the plasma pharmacokinetics ( $\mathrm{AUC}$ and $\mathrm{C}_{\max }$ ) of atorvastatin equivalents, measured as all compounds capable of inhibiting HMG-CoA reductase, showed nonlinear increases. However, in a multiple-dose study [25], a greater than dose-proportional increase was observed only in the $\mathrm{C}_{\max }$ but not in the AUC of either atorvastatin or its active metabolites. In this multiple-dose study, atorvastatin concentrations were assayed by a gas chromatography/mass spectrometry (GC/MS) method. The difference between the atorvastatin-equivalent concentration and atorvastatin concentration represented the sum of the concentrations of active metabolites.

A new Small Tablet (ST) formulation, which is round-shaped, filmcoated, and about 33\% smaller in size than the Marketed Tablet (MT) formulation, has been developed with the main objective to ease patient administration, particularly the elderly who have swallowing difficulties. Additionally, a Chewable Tablet (CT) formulation has been developed as an alternative formulation of atorvastatin, which is also age-appropriate for use in the pediatric population.

The criteria for establishing bioequivalence (BE) of orally administered drug products include Test/Reference comparisons of both $\mathrm{C}_{\text {max }}$ and AUC as the indicators of peak and extent of exposures, respectively.
According to EMA [7] in studies to determine bioequivalence after a single dose, the parameters to be analyzed are $\mathrm{AUC}_{\text {last }}$, or, when relevant, $\mathrm{AUC}_{72 \mathrm{~h}}$, and $\mathrm{C}_{\max }$. In studies with a sampling period of $72 \mathrm{~h}$, and where the concentration at $72 \mathrm{~h}$ is quantifiable, $\mathrm{AUC}_{\text {inf }}$ and residual area do not need to be reported; it is sufficient to report AUC truncated at $72 \mathrm{~h}, \mathrm{AUC}_{72 \mathrm{~h}}$. A statistical evaluation of $\mathrm{T}_{\max }$ is not required unless rapid release is claimed to be clinically relevant and of importance for onset of action or is related to adverse events $[19,9,11,7]$. Regulatory authorities such as United States Food and Drug Administration (FDA), European Medicines Agency (EMA), and Health Canada Therapeutic Products Directorate (TPD) generally recommend that the parent drug released from the dosage form, rather than the metabolites, be used as the basis for $\mathrm{BE}$ determination. The rationale for this recommendation is that concentration-time profile of the parent drug is more sensitive to the changes in formulation performance than a metabolite which is more reflective of metabolite formation, distribution, and elimination. In the case of drugs whose metabolites contribute meaningfully to safety and/ or efficacy, some regulatory agencies such FDA and TPD require the determination of the BE based on the parent drug as well as the submission of metabolite data as supportive information [13,8]. However, the position of the EMA regarding the consideration of active metabolites for $\mathrm{BE}$ assessment has been evolving up to the finalization of the current $\mathrm{BE}$ guideline which only requires the analysis of the parent drug in $\mathrm{BE}$ studies [5,7]. In the current EMA guidance [7], the EMA clearly specifies the $\mathrm{C}_{\max }$ of the parent compound is usually more sensitive in detecting differences between formulations in absorption rate rather than the

*Corresponding author: Kuan Gandelman, Pfizer Inc, 235 East 42nd Street, NewYork, NY 10017, USA, Tel: 212-733-6258; Fax: 860-715-9320; E-mail: kuan. gandelman@pfizer.com

Received February 22, 2011; Accepted May 13, 2011; Published May 25, 2011

Citation: Gandelman K, Malhotra B, LaBadie RR, Crownover P, Bergstrom T (2011) Analytes of Interest and Choice of Dose: Two Important Considerations in the Design of Bioequivalence Studies with Atorvastatin. J Bioequiv Availab 3: 062 068. doi:10.4172/jbb.1000060

Copyright: ( 2011 Gandelman K, et al. This is an open-access article distributed under the terms of the Creative Commons Attribution License, which permits unrestricted use, distribution, and reproduction in any medium, provided the original author and source are credited. 
$\mathrm{C}_{\max }$ of a metabolite. It also clarifies further that the active metabolites do not need to be measured unless it is not feasible to measure parent drug concentrations.

Also according to Biopharmaceutics Classification System (BCS) based biowaivers $[19,7,9]$, for the immediate release test products with proportionally formulated strengths, high soluble drugs with or without high permeability (i.e., BCS Class I and III drugs, respectively) can be exempted from in vivo $\mathrm{BE}$ studies and rely on in vitro dissolution methods as surrogates. For other BCS Class of drugs (e.g., BCS Class II and IV drugs), to demonstrate BE for all strengths, it is required to conduct one clinical BE study (the one which is most sensitive to formulation differences), provided that certain conditions for the test product are met. The EMA and TPD do not have specific BE guidance for atorvastatin. Also their general positions regarding the selection of the dose strengths for $\mathrm{BE}$ studies have been evolving until recently. The EMA's BE guideline was finalized in January 2010 [5,6]. The TPD nonlinear drug guidance issued 2003 [10], and the TPD draft BE guidance issued January 2010 [11]. In the EMA draft guidance [5,6], a linear pharmacokinetic was defined as a proportional increase in AUC and $\mathrm{C}_{\max }$ with the increased dose over the therapeutic dose range. It also recommended that in the case of a linear PK that could not be concluded from the available data, the Sponsors need to conduct $\mathrm{BE}$ studies at both the lowest dose using the lowest strength and the highest dose using the highest strength. Similarly, in the current TPD BE guideline [9] it specifies "for some of the complicated drugs --such as those with ...non-linear kinetics....--the bioavailability of each strength of the drug should be established," whereas in the TPD nonlinear draft guidance [10], a detailed decision tree toward various nonlinear pharmacokinetic situations was specified.

Global regulatory opinions on the measurement of active metabolites and on the selection of the dose strength(s) to be studied for $\mathrm{BE}$ assessments were still evolving during the time when the studies to support the development of atorvastatin ST and CT formulations were conducted. During this period, there are many examples of other drugs, including pioglitazone and risperidone, where both parent and active metabolites were evaluated in the BE studies [24,1]. The pharmacokinetics of ortho-hydroxyatorvastatin, the principal active metabolite of atorvastatin, were analyzed in the BE studies for the CT formulation, but not in studies for the ST formulation. This paper presents the analyses that were used to determine whether metabolite data provide additional informative value in the assessment of the $\mathrm{BE}$ of new atorvastatin formulations. Additionally, we assessed the linearity of atorvastatin pharmacokinetics to determine the need to adopt a bracketing approach for establishing the atorvastatin for new formulations at several strengths, i.e., the need to evaluate atorvastatin $\mathrm{BE}$ at the lowest $(10 \mathrm{mg})$ and the highest $(80 \mathrm{mg})$ strengths.

\section{Materials and Methods}

\section{Study design}

There were four individual BE studies; each conducted as an openlabel, single-dose, randomized, 2-way crossover study, with a 14-day washout period between doses. Eligible adult subjects were admitted to the clinical research unit on Day 0 of each period. On Day 1 of each period, following an overnight 8 -hour fast, subjects received a single dose of the atorvastatin reference tablets or the test tablets with $240 \mathrm{~mL}$ of ambient temperature water according to a randomization schedule. Study treatment was administered under the supervision of investigator site personnel. For the CT formulations, subjects must chew the study treatment and then drink water. For the ST and MT formulations, subjects were to swallow the study treatment whole with water. The oral cavity of each subject was examined following dosing to ensure the study treatment was completely ingested. Subjects must abstain from all food and drink (except water) at least 4 hours prior to any safety laboratory evaluations and 8 hours prior to the start of pharmacokinetic sample collections. Water was permitted until 1 hour prior to study medication administration. Water may be consumed without restriction beginning 1 hour after dosing. Lunch and dinner were provided approximately 4 and 9-10 hours after dosing, respectively. The total daily nutritional composition was approximately 50\% carbohydrate, 35\% fat and 15\% protein. The daily caloric intake per subject was less than $3200 \mathrm{kcal}$. In order to standardize the conditions on PK sampling days, all subjects were required to refrain from lying down during the first 4 hours after dosing.

The test products were atorvastatin ST at the doses of 1 X10 mg (batch No. 08-066359, production date Apr. 2008, expiration date Apr. 2009) in Study A and 1 X80 mg (batch No. 08-066360, production date Apr. 2008, expiration date Apr. 2009) in Study B; or atorvastatin CT at the doses of 1 X10 mg (batch No. 08-069701, production date Mar. 2008, expiration date Mar. 2012) in Study C, and 2X $40 \mathrm{mg}$ (80 mg) (batch No. 08-069700, production date Mar. 2008, expiration date Nov. 2010) in Study D. The reference product was atorvastatin MT at the respective 1X10 mg (batch No. 08-064783, expiration date Nov. 2010) or 1X80 mg (batch No. 08-064786, expiration date Nov. 2010) dose in ST studies as well as $1 \mathrm{X} 10 \mathrm{mg}$ (batch No. 08-066007, expiration date Feb. 2012) or 1X80 mg (batch No. 08-064786, expiration date Nov. 2010) dose in CT studies. Blood samples for PK analyses were obtained pre-dose and at $0.25,0.5,1,1.5,2,3,4,6,9,12,24,36,48$, and 72 hours after each dose.

\section{Subjects}

These studies were each conducted in healthy adult male and female subjects aged 18 to 55 years (inclusive) with a body mass index between 18 and $30 \mathrm{~kg} / \mathrm{m}^{2}$ (inclusive). The protocol for each study was approved by the Independent Review Board of the clinical site and the studies were conducted in full compliance with the principles of the Declaration of Helsinki and International Conference on Harmonization (ICH) Good Clinical Practice (GCP) Guidelines.

\section{Pharmacokinetic and statistical analyses}

Plasma concentrations of atorvastatin and/or orthohydroxyatorvastatin were determined at Advion Bioservices, Ithaca, NY, by liquid chromatography tandem mass spectrometric (LC/MS/ MS) method, as previously described [2]. Currently there are two validated LC/MS/MS assays, each with different assay ranges and limit of quantification (LOC). The assay with a linear range of $0.100 \mathrm{ng} / \mathrm{mL}$ to $10.0 \mathrm{ng} / \mathrm{mL}$ and a lower limit of quantification (LLOQ) of $0.100 \mathrm{ng} /$ $\mathrm{mL}$ was used in the $10 \mathrm{mg} \mathrm{ST}$ and CT studies (Study A and Study C). The assay with a linear range of 0.250 to $100 \mathrm{ng} / \mathrm{mL}$ and LLOQ of 0.250 $\mathrm{ng} / \mathrm{mL}$ was used in the $80 \mathrm{mg} \mathrm{ST}$ and CT studies (Study B and Study D).

Noncompartmental pharmacokinetic analyses which do not require the assumption of a specific compartmental model were performed on the plasma concentration-time profiles of individual subjects. The PK parameters analyzed include area under plasma concentration-time profile from time zero extrapolated to infinite time $\left(\mathrm{AUC}_{\text {inf }}\right)$, area under the plasma concentration-time profile from time zero to the time of the last quantifiable concentration $\left(\mathrm{AUC}_{\text {last }}\right)$, and maximum plasma 
Citation: Gandelman K, Malhotra B, LaBadie RR, Crownover P, Bergstrom T (2011) Analytes of Interest and Choice of Dose: Two Important Considerations in the Design of Bioequivalence Studies with Atorvastatin. J Bioequiv Availab 3: 062-068. doi:10.4172/jbb.1000060

concentration $\left(\mathrm{C}_{\max }\right)$. The estimation of AUC was completed by linear/ log trapezoidal method which use the linear trapezoidal rule during the ascending phase to the first occurrence of $\mathrm{C}_{\max }$ and the log trapezoidal rule during the descending phase. Natural-log transformed $\mathrm{AUC}_{\text {inf }}$ $\mathrm{AUC}_{\text {last }}$, and $\mathrm{C}_{\max }$ were analyzed by analysis of variance (ANOVA) using a mixed effects model with sequence, period, and treatment as fixed effects and subject-within-sequence as a random effect. Estimates of the adjusted mean differences (Test-Reference) and corresponding $90 \%$ confidence intervals (CIs) were obtained, and the adjusted mean differences and $90 \%$ CIs for the differences were exponentiated to provide estimates of the ratio of adjusted geometric means (Test/ Reference) and $90 \%$ CIs for the ratios. The BE of the Test to Reference

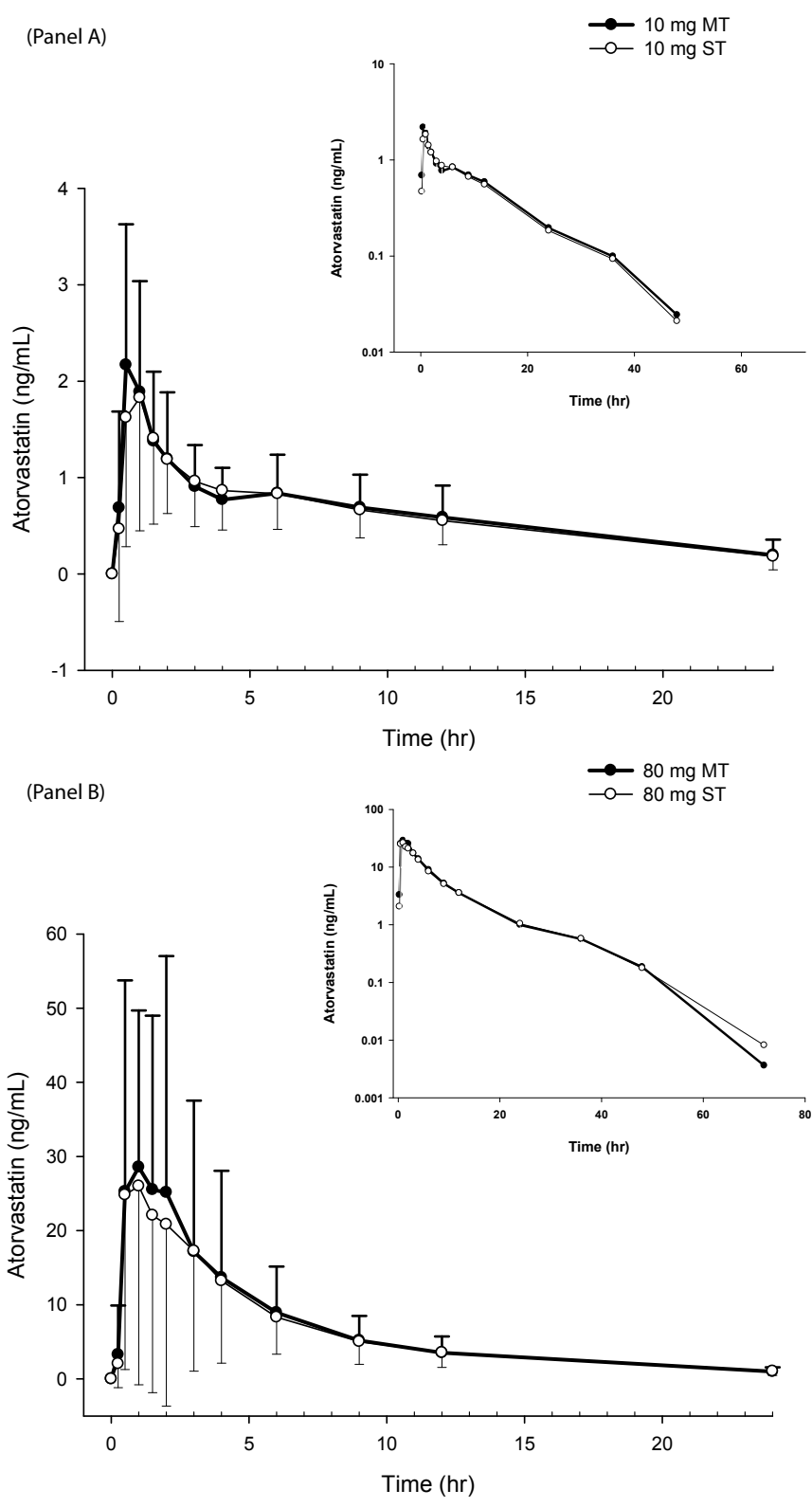

Figure 1: Mean plasma concentration-time profiles of atorvastatin following the administration of $10 \mathrm{mg}$ (Panel A) and $80 \mathrm{mg}$ (Panel B) atorvastatin doses as Small Tablet (ST) vs. Marketed Tablet (MT). Inset depicts the same data on a semilogarithmic scale over the 72-hour sampling duration.
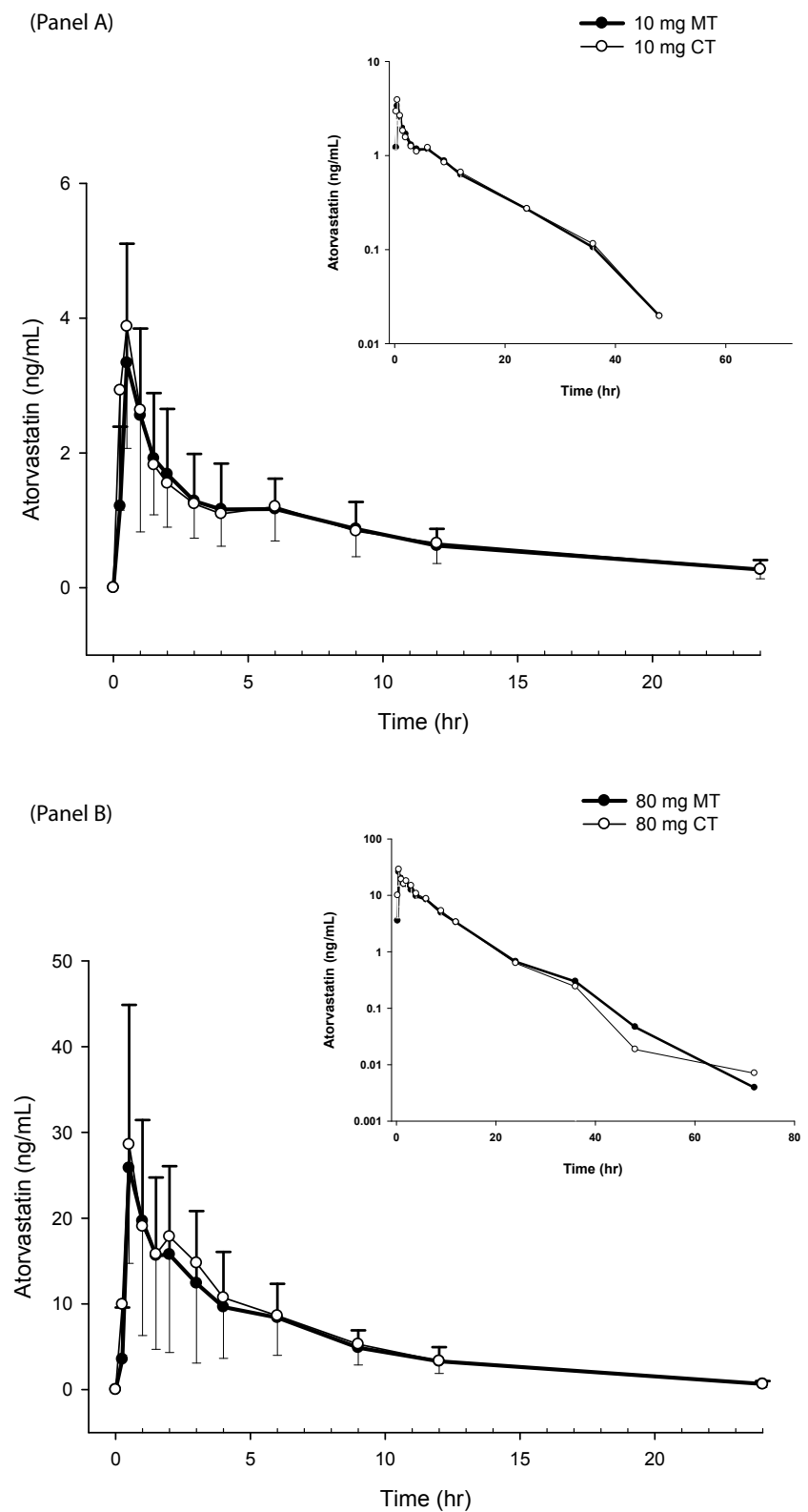

Figure 2: Mean plasma concentration-time profiles of atorvastatin following the administration of $10 \mathrm{mg}$ (Panel A) and $80 \mathrm{mg}$ (Panel B) atorvastatin doses as Chewable Tablet (CT) vs. Marketed Tablet (MT). Inset depicts the same data on a semilogarithmic scale over the 72 -hour sampling duration.

was to be concluded if the $90 \%$ CIs for the ratios (Test/Reference) of adjusted geometric means for $\mathrm{AUC}_{\mathrm{inf}}, \mathrm{AUC}_{\text {last }}$ and $\mathrm{C}_{\max }$ of atorvastatin fell entirely within $(80 \%, 125 \%)$.

A sample size of 74 subjects was determined to provide $99 \%$ and $91 \%$ power that the $90 \%$ CI for the ratio of Test to Reference treatment for $\mathrm{AUC}_{\text {inf }}$ and $\mathrm{C}_{\text {max }}$, respectively, would lie within the acceptance region of $(80 \%, 125 \%)$ This estimate was based on the assumption that the true ratio between Test and Reference treatments for both $\mathrm{AUC}_{\text {inf }}$ and $\mathrm{C}_{\max }$ was 1.05 and also assumed within-subject standard deviations (SD) of 0.185 and 0.35 for loge $\mathrm{AUC}_{\text {inf }}$ and loge $\mathrm{C}_{\max }$, respectively, as obtained from the average of 10 previous studies. 

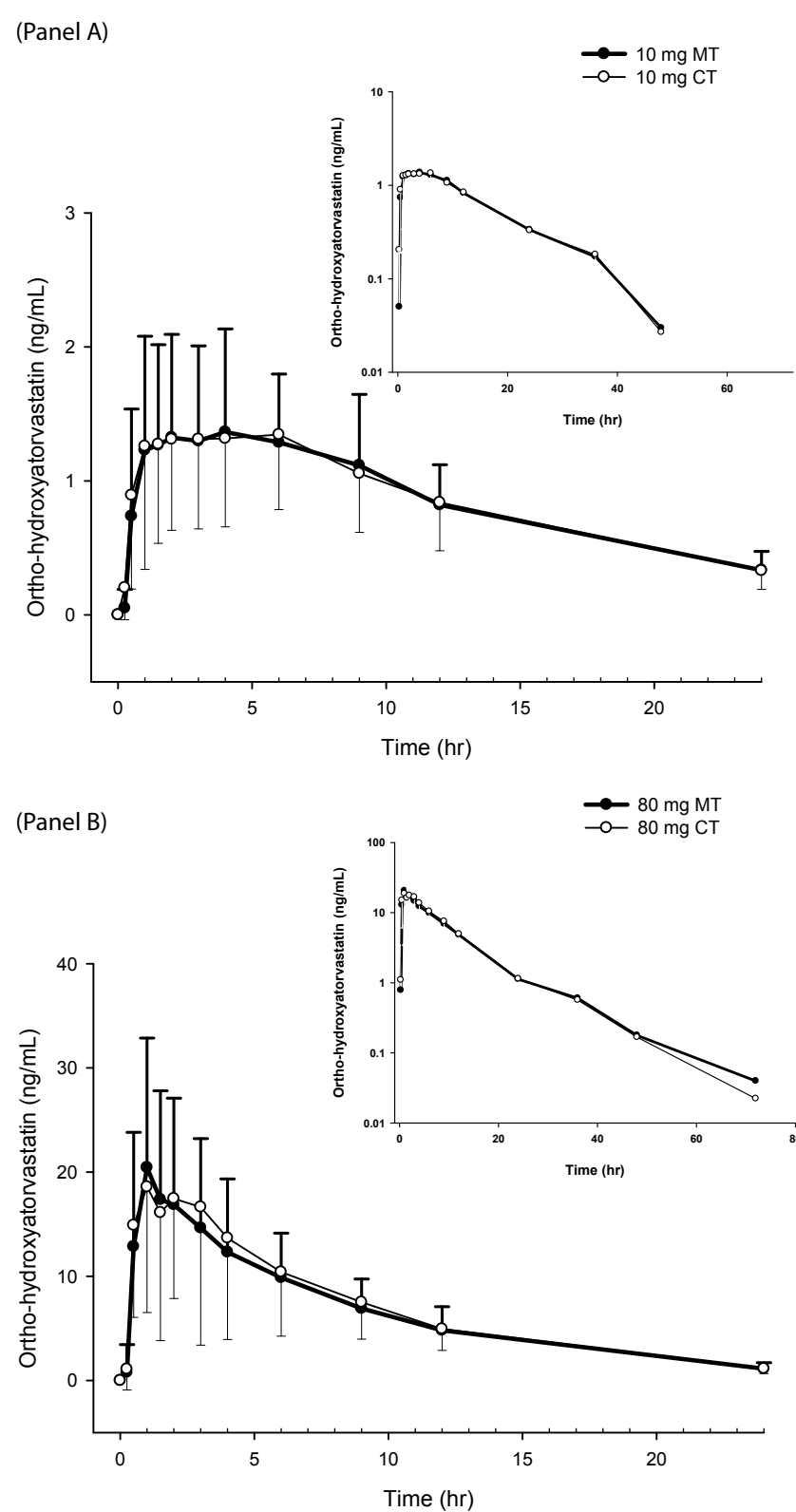

Figure 3: Mean plasma concentration-time profiles of ortho-hydroxyatorvastatin following the administration of $10 \mathrm{mg}$ (Panel A) and $80 \mathrm{mg}$ (Panel B) atorvastatin doses as Chewable Tablet (CT) vs. Marketed Tablet (MT). Inset depicts the same data on a semilogarithmic scale over the 72-hour sampling duration.

\section{Safety}

The safety and tolerability was evaluated by vital signs monitoring, physical examinations, 12-lead ECGs, and subject interviews on adverse events (AEs).

\section{Results}

\section{Subject characteristics}

A total of 76 healthy volunteers were assigned to receive study treatment in each study, and a total of 74, 73, 72, and 70 subjects completed Study A, Study B, Study C, and Study D, respectively. The ST studies (Study A; Study B) conducted at the same study center in
United States had comparable demographic characteristics: number of male/female subjects $(38 / 38 ; 41 / 35)$; mean age, years $(37 ; 41)$, mean weight, $\mathrm{kg}(71 ; 74)$, and race (White $93 \%$; White $93 \%)$. In contrast, the CT studies (Study C; Study D) conducted at different study centers in different countries had somewhat different demographic characteristics: number of male/female subjects $(70 / 6 ; 59 / 17)$, mean age, years $(28 ; 36)$, mean weight kg (66; 79), and race (Asian 75\%; Black/White: 46\%/16\%).

\section{Pharmacokinetics}

The mean plasma concentration-time profiles of atorvastatin following the administration of $10 \mathrm{mg}$ and $80 \mathrm{mg}$ given as ST or CT formulations, were superimposable on those following the administration of MT formulation at the respective dose (Figure 1 and Figure 2), respectively. Median $\mathrm{T}_{\max }$ [hour (range)] were similar between ST vs MT: $10 \mathrm{mg}$ [1.0 (0.25-9.0) vs $0.5(0.25-4.0)], 80 \mathrm{mg}$ [1.0 (0.5-4.0) vs $1.0(0.5-4.0)]$ as well as between CT vs MT treatments: 10 mg [0.5 (0.25-1.5) vs $0.5(0.4-4.0)], 80 \mathrm{mg}$ [0.5 (0.25-6.0) vs 0.5 (0.56.0)]. Similar results were obtained for ortho-hydroxyatorvastatin in the CT studies (Figure 3). Median $\mathrm{T}_{\max }$ [hour (range)] of orthohydroxyatorvastatin were similar between CT vs MT treatments: $10 \mathrm{mg}$ [4.0 (0.5-9.0) vs $3.5(0.5-9.0)], 80 \mathrm{mg}$ [1.0 (0.5-6.0) vs $1.0(0.5-6.0)]$. Of note, following the administration of $10 \mathrm{mg}$ ST or CT formulations, plasma concentrations of atorvastatin and ortho-hydroxyatorvastatin were mostly not quantifiable at $72 \mathrm{~h}$. Thus $\mathrm{AUC}_{\text {inf }}$ instead of $\mathrm{AUC}_{72 \mathrm{~h}}$ was reported in these studies. A statistical summary of treatment comparisons of $\mathrm{AUC}_{\text {inf }}, \mathrm{AUC}_{\text {last }}$ and $\mathrm{C}_{\max }$ is presented in Table 1. The $90 \%$ CIs for the ratio of the adjusted geometric means for $\mathrm{AUC}_{\text {inf }}$ $\mathrm{AUC}_{\text {last }}$, and $\mathrm{C}_{\max }$ of atorvastatin were completely within $(80 \%, 125 \%)$, the acceptance range for concluding $\mathrm{BE}$. In addition, the corresponding 90\% CIs for ortho-hydroxyatorvastatin measurements in the CT studies were also completely within the bioequivalent limits.

For the assessment of dose-relationship of the exposures of atorvastatin and its principal metabolite, when compared across $10 \mathrm{mg}$ and $80 \mathrm{mg}$ of ST and CT studies, as shown in Table 1, a greater than dose-proportional increase is generally seen in $\mathrm{C}_{\max }$ but not AUC. In the ST studies with the 8 -fold increase in dose, the AUC shows proportional increase (about 9-fold) whereas $\mathrm{C}_{\max }$ of atorvastatin exhibits a greater than proportional increase (about 14- to 16-fold) in both groups. In the CT studies, with the 8-fold increase in dose, the AUC of both atorvastatin and ortho-hydroxyatorvastatin increased proportionally (about 6.5-fold); the $\mathrm{C}_{\text {max }}$ of ortho-hydroxyatorvastatin, however, shows a greater than proportional increase (about 15-fold). In addition, when compared across studies, the AUC ratios of ortho-hydroxyatorvastatin vs. atorvastatin for both groups in the CT studies are about 1.1-1.3, with no apparent dose relationship.

\section{Safety}

Both $10 \mathrm{mg}$ and $80 \mathrm{mg}$ dose given as ST, CT, and MT formulations were generally safe and well-tolerated in adult healthy volunteers. Overall, the AE profiles were consistent with the product label of atorvastatin. There were no deaths or serious AEs reported in these studies. There were no study discontinuations due to an $\mathrm{AE}$ that considered treatment related.

\section{Discussion}

The results of these four studies showed that the ST and the CT formulations of atorvastatin were each bioequivalent to the current MT formulation, at the lowest $(10 \mathrm{mg})$ and the highest $(80 \mathrm{mg})$ doses. 
Citation: Gandelman K, Malhotra B, LaBadie RR, Crownover P, Bergstrom T (2011) Analytes of Interest and Choice of Dose: Two Important Considerations in the Design of Bioequivalence Studies with Atorvastatin. J Bioequiv Availab 3: 062-068. doi:10.4172/jbb.1000060

\begin{tabular}{|c|c|c|c|c|c|c|c|c|}
\hline \multirow{2}{*}{ Study } & \multirow{2}{*}{$\begin{array}{l}\text { Dose } \\
\text { (mg) }\end{array}$} & \multirow{2}{*}{$\begin{array}{l}\text { Parameter } \\
\text { (units) }\end{array}$} & \multirow{2}{*}{ Analyte } & \multicolumn{2}{|c|}{ Adjusted Geometric Mean (SD) Min; Max } & \multirow{2}{*}{$\begin{array}{l}\text { Ratio (Test/Reference) of Adjusted } \\
\text { Geometric Mean (\%) }\end{array}$} & \multicolumn{2}{|c|}{$90 \%$ Confidence Intervals (\%) } \\
\hline & & & & Test & Reference & & Lower & Upper \\
\hline \multirow{3}{*}{ ST vs. MT } & \multirow{3}{*}{10} & $\begin{array}{l}\mathrm{AUC}_{\text {inf }}(\mathrm{ng} \cdot \mathrm{h} / \\
\mathrm{mL})\end{array}$ & ATV & $\begin{array}{l}16.73(8.26) \\
5.90 ; 42.20\end{array}$ & $\begin{array}{l}17.55(8.80) \\
5.68 ; 51.40\end{array}$ & 95.34 & 91.33 & 99.52 \\
\hline & & $\begin{array}{l}\text { AUC } \text { last }_{\text {(ng.h/mL) }} \\
\text { (nthe }\end{array}$ & ATV & $\begin{array}{l}14.02(7.89) \\
4.42 ; 39.50\end{array}$ & $\begin{array}{l}17.55(8.72) \\
4.73 ; 48.20\end{array}$ & 95.79 & 91.07 & 100.76 \\
\hline & & $\mathrm{C}_{\max }(\mathrm{ng} / \mathrm{mL})$ & ATV & $\begin{array}{l}2.34(1.45) \\
0.78 ; 8.23\end{array}$ & $\begin{array}{l}2.56(1.23) \\
0.96 ; 5.97\end{array}$ & 91.41 & 83.39 & 100.20 \\
\hline \multirow{3}{*}{ ST vs. MT } & \multirow{3}{*}{80} & $\begin{array}{l}\mathrm{AUC} \\
\mathrm{mL} \text { ) }\end{array}$ & ATV & $\begin{array}{l}151.03(100.78) \\
66.00 ; 794.00\end{array}$ & $\begin{array}{l}152.88(120.19) \\
57.90 ; 864.00\end{array}$ & 98.79 & 94.57 & 103.20 \\
\hline & & $\begin{array}{l}\mathrm{AUC}_{\text {last }} \\
\text { (ng.h/mL) }\end{array}$ & ATV & $\begin{array}{l}144.94(100.57) \\
58.40 ; 786.00\end{array}$ & $\begin{array}{l}146.81(119.71) \\
51.80 ; 856.00\end{array}$ & 98.72 & 94.41 & 103.23 \\
\hline & & $\mathrm{C}_{\max }(\mathrm{ng} / \mathrm{mL})$ & ATV & $\begin{array}{l}36.38(31.71) \\
9.34 ; 193.00\end{array}$ & $\begin{array}{l}34.76(36.47) \\
7.25 ; 224.00\end{array}$ & 104.66 & 95.73 & 114.42 \\
\hline \multirow{6}{*}{ CT vs. MT } & \multirow{6}{*}{10} & \multirow{2}{*}{$\begin{array}{l}\mathrm{AUC}_{\text {inf }}(\mathrm{ng} \cdot \mathrm{h} / \\
\mathrm{mL})\end{array}$} & ATV & $\begin{array}{l}22.78(9.73) \\
9.05 ; 61.70\end{array}$ & $\begin{array}{l}22.13(9.68) \\
9.83 ; 65.80\end{array}$ & 102.91 & 99.02 & 106.96 \\
\hline & & & O-ATV & $\begin{array}{l}24.46(9.52) \\
10.10 ; 72.40\end{array}$ & $\begin{array}{l}24.30(9.67) \\
10.40 ; 70.50\end{array}$ & 100.64 & 97.51 & 103.88 \\
\hline & & \multirow{2}{*}{$\begin{array}{l}\text { AUC } \\
(\mathrm{ng} \cdot \mathrm{h} / \mathrm{mL})\end{array}$} & ATV & $\begin{array}{l}20.48(9.57) \\
7.31 ; 60.10\end{array}$ & $\begin{array}{l}19.80(9.26) \\
7.00 ; 64.30\end{array}$ & 103.48 & 99.34 & 107.79 \\
\hline & & & O-ATV & $\begin{array}{l}16.73(9.59) \\
7.52 ; 70.60\end{array}$ & $\begin{array}{l}16.73(9.71) \\
8.52 ; 68.40\end{array}$ & 101 & 97.68 & 104.44 \\
\hline & & \multirow{2}{*}{$\mathrm{C}_{\max }(\mathrm{ng} / \mathrm{mL})$} & ATV & $\begin{array}{l}3.80(2.22) \\
1.45 ; 14.30\end{array}$ & $\begin{array}{l}3.51(1.58) \\
1.13 ; 8.70\end{array}$ & 108.13 & 98.75 & 118.40 \\
\hline & & & O-ATV & $\begin{array}{l}1.49(0.86) \\
0.48 ; 5.32\end{array}$ & $\begin{array}{l}1.52(0.91) \\
0.57 ; 5.54\end{array}$ & 97.98 & 92.34 & 103.96 \\
\hline \multirow{6}{*}{ CT vs. MT } & \multirow{6}{*}{80} & \multirow{2}{*}{$\begin{array}{l}\mathrm{AUC}_{\text {inf }} \text { (ng.h/ } \\
\mathrm{mL})\end{array}$} & ATV & $\begin{array}{l}131.13(58.71) \\
64.20 ; 364.00\end{array}$ & $\begin{array}{l}124.03(53.83) \\
60.00 ; 317.00\end{array}$ & 105.73 & 100.69 & 111.02 \\
\hline & & & O-ATV & $\begin{array}{l}163.8(75.99) \\
54.90 ; 514.00\end{array}$ & $\begin{array}{l}156.5(69.81) \\
64.70 ; 472.00\end{array}$ & 104.65 & 100.40 & 109.08 \\
\hline & & \multirow{2}{*}{$\begin{array}{l}\mathrm{AUC} \\
\mathrm{mL})\end{array}$} & ATV & $\begin{array}{l}127.49(59.13) \\
60.60 ; 363.00\end{array}$ & $\begin{array}{l}120.79(53.36) \\
57.60 ; 313.00\end{array}$ & 105.55 & 100.34 & 111.03 \\
\hline & & & O-ATV & $\begin{array}{l}159.16(74.69) \\
51.20 ; 492.00\end{array}$ & $\begin{array}{l}151.88(69.19) \\
61.40 ; 461.00\end{array}$ & 104.79 & 100.41 & 109.37 \\
\hline & & \multirow{2}{*}{$\mathrm{C}_{\max }(\mathrm{ng} / \mathrm{mL})$} & ATV & $\begin{array}{l}29.24(15.88) \\
7.02 ; 91.50\end{array}$ & $\begin{array}{l}28.85(16.15) \\
9.27 ; 99.20\end{array}$ & 101.37 & 92.39 & 111.23 \\
\hline & & & O-ATV & $\begin{array}{l}22.52(15.82) \\
7.29 ; 95.30\end{array}$ & $\begin{array}{l}22.28(12.22) \\
6.60 ; 63.20\end{array}$ & 101.11 & 93.08 & 109.84 \\
\hline
\end{tabular}

ATV=atorvastatin acid; O-ATV=ortho-hydroxyatorvastatin acid

Table 1: Statistical summary of pharmacokinetic parameters of atorvastatin and ortho-hydroxyatorvastatin in healthy subjects following single-dose administration of 10 and $80 \mathrm{mg}$ doses as Small Tablet (ST) or Chew Tablet (CT) vs. Marketed Tablet (MT).

For the CT formulation, both atorvastatin and its metabolite were analyzed, and the two moieties led to the same conclusion of $\mathrm{BE}$ at both doses. However, for the ST formulation BE was determined only for atorvastatin, as the analyses were only done on atorvastatin. In the ST formulation BE would also be predicted for the metabolite, due to the fact that the ST and CT formulations are remarkably similar and furthermore the ST formulation is closer in composition to MT as compared to ST. Even though excipients are known to influence the drug dissolution and/or absorption [12,7], as stated above the similarities in formulations would not support alterations in BE for the metabolite among these formulations. Especially, the ST formulation was a lower-weight and 33\% smaller-size tablet made of essentially the same granulation as the reference MT formulation. The $80 \mathrm{mg}$ ST used the same drug substance and excipients contained in the MT; the 10, 20 , and $40 \mathrm{mg}$ ST also used the same percentages of drug substance and excipients as the MT formulation (10,20 and, $40 \mathrm{mg}$ ), with exception of candelilla wax. This type of formulation change is unlikely to affect the metabolite formation. As a result the level of formulation modification in the ST formulation compared to that involved in the CT formulation was considered unlikely to affect the metabolite formation or to result in different $\mathrm{BE}$ outcomes of ortho-hydroxyatorvastatin; therefore, ortho-hydroxyatorvastatin was not analyzed in the ST studies.

Based on single- and multiple-dose studies, it can be concluded that the atorvastatin AUC increases proportionally with dose, and

its nonlinearity is associated with $\mathrm{C}_{\max }$ only. The multiple-dose study described in the literature [25] was a sequential dose-escalation design, which showed a greater than dose-proportional increase in $\mathrm{C}_{\text {max }}$ but not in the AUC of atorvastatin as well as its active metabolites. The four ST and CT studies described here were conducted using similar singledose, two-way crossover study design and were analyzed similarly, allowing for between-study assessment of dose proportionality. For the 8 -fold dose increment between the 10 - and $80-\mathrm{mg}$ doses given as ST, CT and MT formulations across these four studies, the $\mathrm{C}_{\max }$ and AUC ratios were 7.7-15.5 and 5.6-9.0 fold, respectively, indicating doseproportional $\mathrm{AUC}$ and greater-than-proportional $\mathrm{C}_{\max }$, consistent with the multiple-dose study results of dose proportionality.

Furthermore the analyses of the metabolite/parent ratios of AUC across the CT studies showed no apparent dose relationship in the AUC ratios of ortho- hydroxyatorvastatin/atorvastatin for both formulation groups (i.e., 1.1 and 1.3 at $10 \mathrm{mg}$ and $80 \mathrm{mg}$ atorvastatin doses, respectively). These results are also consistent with those of the multiple-dose study [25] in which the metabolite/parent ratios did not appear dose-related $(2.1,2.4,1.5$, and 2.7 following $10,20,40$, and $80 \mathrm{mg}$ atorvastatin doses, respectively). These results imply that the metabolic clearance of atorvastatin is not saturable across the $10-80 \mathrm{mg}$ doses; any differences in metabolite exposures due to a formulation change will be reflected in the systemic exposures of the parent drug.

Atorvastatin exhibits a complex pharmacokinetic profile: a greater 
Citation: Gandelman K, Malhotra B, LaBadie RR, Crownover P, Bergstrom T (2011) Analytes of Interest and Choice of Dose: Two Important Considerations in the Design of Bioequivalence Studies with Atorvastatin. J Bioequiv Availab 3: 062-068. doi:10.4172/jbb.1000060

than proportional increase in $\mathrm{C}_{\max }$ only, high intra-subject variability in $\mathrm{C}_{\max }$, and its active metabolites contribute significantly to safety and efficacy. It is a BCS Class II drug (low solubility, high permeability drug) [23] and the FDA has recently specified the required studies to support abbreviated new drug applications (ANDA) of 10-80 mg doses of generic atorvastatin [20]. The guidance requires atorvastatin BE study at the highest dose, with a provision of biowaiver for $10 \mathrm{mg}, 20 \mathrm{mg}$, and $40 \mathrm{mg}$ atorvastatin, the generic companies need to show (1) acceptable clinical BE studies on the $80 \mathrm{mg}$ strength, (2) proportionally similar across all strengths, and (3) acceptable in vitro dissolution testing of all strengths. In general, the product-specific BE guidelines by FDA require $\mathrm{BE}$ studies at the highest dose strength permissible by safety in healthy subjects and also emphasize the measurement of metabolites for products which derive significant pharmacological effects from active metabolite(s). For example, it requires $\mathrm{BE}$ evaluation under both fasting and fed conditions with $80 \mathrm{mg}$ (highest strength) simvastatin and to provide beta-OH metabolite data as supportive evidence of a comparable therapeutic outcome [21]. Similarly it is required to conduct BE with $45 \mathrm{mg}$ (highest strength) pioglitazone and to provide M-IV metabolite data [22].

Although statin therapy is generally safe and well tolerated, the increased systemic exposures associated with high doses may increase the risk for relatively common muscular side effects, such as myalgia, and for rare but potentially severe AEs such as myopathy and rhabdomyolysis [4]. There is a clear dose-response relationship for lipid-lowering effects of atorvastatin. Thus, to ensure equivalence of therapeutic outcomes of new generic formulations, it is important to assess bioequivalence of all relevant active moieties under the most sensitive conditions that can detect potential formulation differences. Both AUC and $\mathrm{C}_{\text {max }}$ are essential measures of $\mathrm{BE}[19,7]$, and further that $\mathrm{C}_{\max }$ is the most sensitive PK parameter to detect differences between formulations [7]. The sources of non-linearity for these measures can be found at different kinetic levels of absorption, distribution, and/ or elimination [14]. Specifically, non-linearity of AUC can be related to dose-dependent elimination and/or bioavailability; non-linearity of $\mathrm{C}_{\max }$ can be related to dose-dependent bioavailability, volume, elimination and/or absorption [17]; in many cases the nonlinearity of AUC would also be manifested in $\mathrm{C}_{\max }$. However, non-linear $\mathrm{C}_{\max }$ may be independent of AUC, if the nonlinearity is driven by absorption rate or distribution volume, and the former driver of $\mathrm{C}_{\max }$ nonlinearity is of particular interest in $\mathrm{BE}$ assessment. When exposure increases more than dose proportionally, for the same difference in dose delivered due to formulation bioavailability differences, a larger difference in exposure will be seen at higher doses, and the highest dose strength will have the largest sensitivity in detecting differences between two products. The development of atorvastatin by Pfizer as the product innovator has been supported by BE studies at both the lowest and highest doses and include PK analyses for active metabolites.

In conclusion, although metabolite $\mathrm{BE}$ is not required, supportive metabolite data may be warranted depending on the degree of divergence in formulations from the marketed atorvastatin formulation. Atorvastatin has linear PK with respect to AUC; however, atorvastatin is clearly nonlinear with respect to $\mathrm{C}_{\max }$. In light of the nonlinearity of $\mathrm{C}_{\max }, \mathrm{BE}$ studies of new atorvastatin formulations should be conducted at the highest dose.

\section{Acknowledgements}

This study was sponsored by Pfizer Inc. The authors would like to acknowledge Gregory Duczynski and Ken Yamamoto (both full-time employees of Pfizer) and Paul Glue (Dunedin School of Medicine, Dunedin, New Zealand) for their contributions to the study and/or manuscript discussion.

\section{Reference}

1. Cánovas M, Delgadillo J, Torres F, Riba N, Cebrecos J, et al. (2009) Bioequivalence evaluation of two strengths of risperidone tablet formulations in healthy volunteers. Int J Clin Pharmacol Ther 47:124-131.

2. Chung M, Calcagni A, Glue P, Bramson C (2006) Effect of food on the bioavailability of amlodipine besylate/atorvastatin calcium combination tablet. $\mathrm{J}$ Clin Pharmacol 46:1212-1216.

3. Cilla DD Jr., Whitfield LR, Gibson DM, Sedman AJ, Posvar EL (1996) Multipledose pharmacokinetics, pharmacodynamics, and safety of atorvastatin, an inhibitor of $\mathrm{H}$ MG-CoA reductase, in healthy subjects. Clin Pharmacol Ther 60:687-695

4. Davidson MH, Robinson JG (2007) Safety of aggressive lipid management. J Am Coll Cardiol 49:1753-1762.

5. European Medicines Agency (2006) Questions \& answers on the note for guidance on the investigation of bioavailability and bioequivalence. EMEACHMP/EWP/40326/2006

6. European Medicines Agency (2008) Guideline on the investigation of bioequivalence (CPMP/EWP/QWP/1401/98 Rev. 1).

7. European Medicines Agency (2010) Guideline on the investigation of bioequivalence (CHMP/EWP/QWP/1401/98 Rev. 1).

8. García MJ, Reinoso RF, Sánchez Navarro A, Prous JR (2003) Clinica pharmacokinetics of statins. Methods Find Exp Clin Pharmacol 25:457-481.

9. Health Canada TPD (1992) Guidance for industry on conduct and analysis of bioavailability and bioequivalence studies Part A: Oral dosage formulations used for systemic effects.

10. Health Canada TPD (2003) Guidance for industry on bioequivalence requirements: drugs exhibiting non-linear pharmacokinetics.

11. Health Canada TPD (2010) Conduct and analysis of comparative bioavailability studies and comparative bioavailability standards: Formulations used for systemic effects.

12. Lee SL, Raw AS, Yu L (2008) Dissolution Testing. In:Krishna R, Yu L (eds) Biopharmaceutics Applications in Drug Development. Springer US Publisher, pp.47-74.

13. Lennernas H (2003) Clinical pharmacokinetics of atorvastatin. Clin Pharmacokinet 42:1141-1160.

14. Mehvar R (2001) Principles of nonlinear pharmacokinetics. American Journal of Pharmaceutical Education 65:178-184.

15. Pfizer Inc. Lipitor ${ }^{\circledR}$ 2009) (atorvastatin calcium) full prescribing information

16. Posvar EL, Radulovic LL, Cilla DD, Whitfield LR, Sedman AJ (1996) Tolerance and pharmacokinetics of single-dose atorvastatin, a potent inhibitor of HMGCoA reductase, in healthy subjects. J Clin Pharmacol 36:728-731.

17. Rowland M, Tozer TN (1995) Extravascular dose. In: Clinical Pharmacokinetics: Concepts and Applications, $3^{\text {rd }}$ edition, Lippincott Williams \& Wilkins Philadelphia, USA, pp.34-46.

18. US FDA (2000) Guidance on waiver of in vivo bioavailability and bioequivalence studies for immediate-release solid oral dosage forms based on a biopharmaceutics classification system. August 2000 .

19. US FDA (2003) Guidance on bioavailability and bioequivalence studies for orally administered drug products - general considerations.

20. US FDA (2008) Office of generic drugs guidance on atorvastatin calcium.

21. US FDA (2008) Office of generic drugs guidance on simvastatin.

22. US FDA (2009) Office of generic drugs guidance on pioglitazone hydrochloride

23. Wu C-Y , Benet LZ (2005) Predicting drug disposition via application of BCS: transport/absorption/elimination interplay and development of a biopharmaceutics drug disposition classification system. Pharm Res 22: 11-23.

24. Wong H, Ozalp Y, Lainesse A, Alpan RS (2004). In-vivo bioequivalence of ora anti-diabetic agents: pioglitazone tablets. Arzneimittelforschung 54: 618-624. 
Citation: Gandelman K, Malhotra B, LaBadie RR, Crownover P, Bergstrom T (2011) Analytes of Interest and Choice of Dose: Two Important Considerations in the Design of Bioequivalence Studies with Atorvastatin. J Bioequiv Availab 3: 062-068. doi:10.4172/jbb.1000060

25. Yang BB, Smithers JA, Stern RH, Sedman AJ, Olson SC (1996) Pharmacokinetics and dose proportionality of atorvastatin and its active metabolites. Pharm Res 9 (Suppl):S437.
26. Newman C, Tsai J, Szarek M, Luo D, Gibson E (2006) Comparative safety of atorvastatin $80 \mathrm{mg}$ versus $10 \mathrm{mg}$ derived from analysis of 49 completed trials in 14,236 patients. Am J Cardiol 97:61-67. 